$\xi=$ 离

\title{
Recurrent isolated tuberculous inguinal lymphadenopathy : A case report and review of literature
}

\author{
Maurice E Asuquo ${ }^{1 *}$, Theophilus Ugbem ${ }^{2}$, Adams D Marwa ${ }^{3}$ \\ ${ }^{1}$ Department of Surgery, University of Calabar, Calabar, Nigeria \\ ${ }^{2}$ Department of Pathology, University of Calabar, Calabar, Nigeria \\ ${ }^{3}$ Department of Surgery, University of Calabar Teaching Hospital, Calabar, Nigeria \\ *Corresponding author E-mail: mauefas@yahoo.com
}

\begin{abstract}
Chronic peripheral lymphadenopathy is indicative of pathology of which tuberculosis is the commonest. Isolated inguinal tuberculous lymphadenitis is a rare finding. Presented is a healthy looking 16 year old human immunodeficiency virus seronegative male with recurrent isolated tuberculous left inguinal lymphadenopathy. Physicians are requested to consider tuberculosis as differential diagnosis of inguinal lymphadenopathy and to subject same to histological evaluation for proper diagnosis and treatment.
\end{abstract}

Keywords: Recurrent; Isolated Inguinal Lymphadenopathy; Tuberculosis.

\section{Introduction}

One-third of the world population is estimated to be affected by tuberculosis $(\mathrm{Tb})$, this is found mostly in the developing countries accounting for a high burden of disease and constituting a major public health problem (Nwagbara V et al 2013, Muleye et al 2013). Peripheral tuberculous lymphadenopathy is the most common form of extra pulmonary $\mathrm{Tb}$ with the cervical lymph nodes as the most common site involved ( NwagbaraV et al 2013, Sing \& Tiwari 2016). It accounts for about $35 \%$ of extra pulmonary $\mathrm{Tb}$ that constitutes $15-20 \%$ of cases of $\mathrm{Tb}$ ( Nwagbara et al 2013). Isolated tuberculous lymphadenopathy is a rare finding described in patients without evidence of previous or active pulmonary $\mathrm{Tb}$ and in addition with no evidence of ongoing $\mathrm{Tb}$ anywhere in the body (Nwagbara et al 2013, Guler et al 2007). In developing countries, chronic peripheral lymphadenopathy (LAP) is indicative of pathology of which $\mathrm{Tb}$ is the commonest (Asuquo et al 2013). The common presenting feature is a palpable mass and the finding of granulomatous features on histology is suggestive of $\mathrm{Tb}$ (Sing \& Tiwari 2016, Asuquo et al 2013). We present this rare case of a recurrent isolated tuberculous left inguinal LAP in a 16 year old male, seronegative for human immunodeficiency virus (HIV) to highlight the Public Health significance, in addition, the need for proper evaluation of peripheral LAP.

\section{Case report}

A 16 year old male presented to the surgical outpatient department with a recurrent left groin swelling of one week duration. He was apparently well until 7 days prior to presentation when he noticed a recurrent swelling of the left groin. Initially, the swelling was the size of a peanut, painless and progressively increased in size. The first episode of this recurrent swelling was 2 years ago which resolved with unspecified medication. Patient admitted to occasional loss of appetite but no history of nausea, vomiting or altered bowel habits. There was no history of associated fever, cough, night sweats, weight loss or contact with patient with chronic cough. Patient did not admit to any history of trauma or swellings of the limbs, gluteus region or lower abdomen. He lives with the parents and 2 female siblings with no similar complain.

Examination revealed an anxious looking male in relative good health, afebrile, not pale, anicteric with no significant peripheral lymphadenopathy (except left inguinal) and no pedal oedema. Chest examination revealed no abnormality. Abdomen was flat, moved with respiration with everted umbilicus. There was a left oval groin mass that measured $5 \times 2 \mathrm{~cm}$; there was no differential warmth, mildly tender, generally firm with a fluctuant area located centrally with limited mobility, Figure 1.

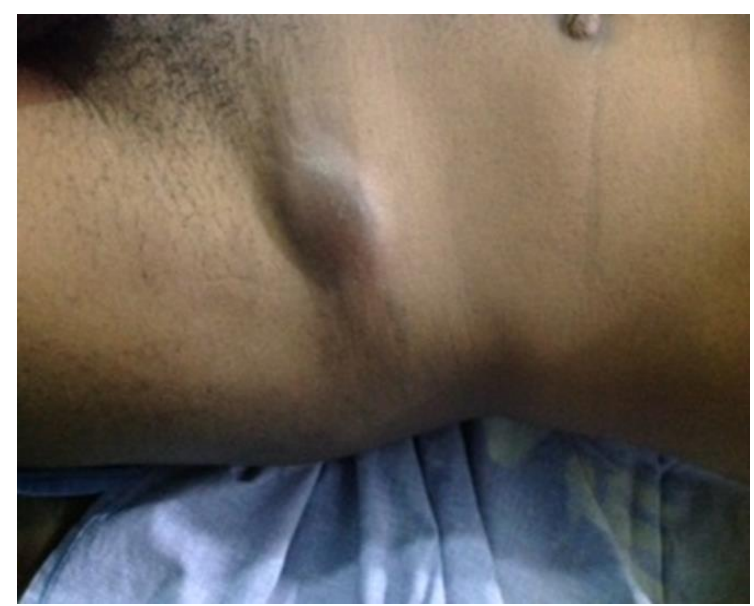

Fig. 1: Clinical Photograph - Left Inguinal Lymphadenopathy.

Digital rectal examination was normal. Left lower limb, the gluteus was normal including the external genitalia. A clinical diagnosis of left inguinal lymphadenopathy was made. 
Full blood count (FBC) showed packed cell volume (PCV) of $36.5 \%$, white blood cells (WBC) of $5.8 \times 10^{9} / 1$ (neutrophils $34.7 \%$, lymphocytes $55.3 \%$, monocytes $7.2 \%$, eosinophils $2.6 \%$, basophils $0.2 \%$ ). Platelet $296 \times 10^{9} / 1$ and ESR $23 \mathrm{~mm} / \mathrm{hr}$. Human immunodeficiency virus (HIV) serology was negative and urinalysis was normal. Chest X-ray was normal while the abdominal ultrasound scan (AUSS) reported a well lobulated mass of lymphoid consistency within the left groin region $(4.5 \times 1.5$ $\mathrm{cm}$ ), no calcification - left inguinal lymphadenopathy.

He was offered an excision biopsy which revealed a mass of $5 \mathrm{x}$ $3 \mathrm{~cm}$, thickened capsule containing casseous substance. Histology reported section that showed mainly mononuclear cells, lymphocytes, plasma cells and neutrophils, congested blood vessels, a few mature adipocytes as well as foreign body giant cells - chronic granulomatous inflammation, Figures $2 \mathrm{a} \& 2 \mathrm{~b}$.

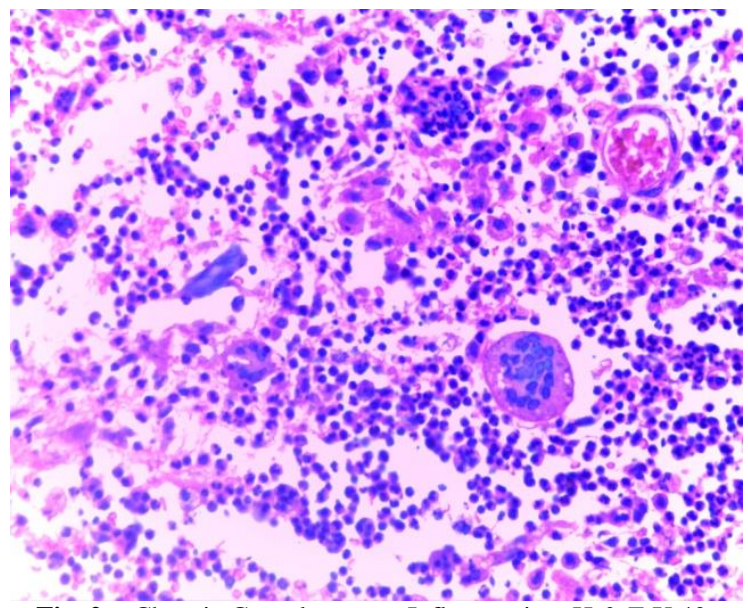

Fig. 2a: Chronic Granulomatous Inflammation, H \& E X 40.

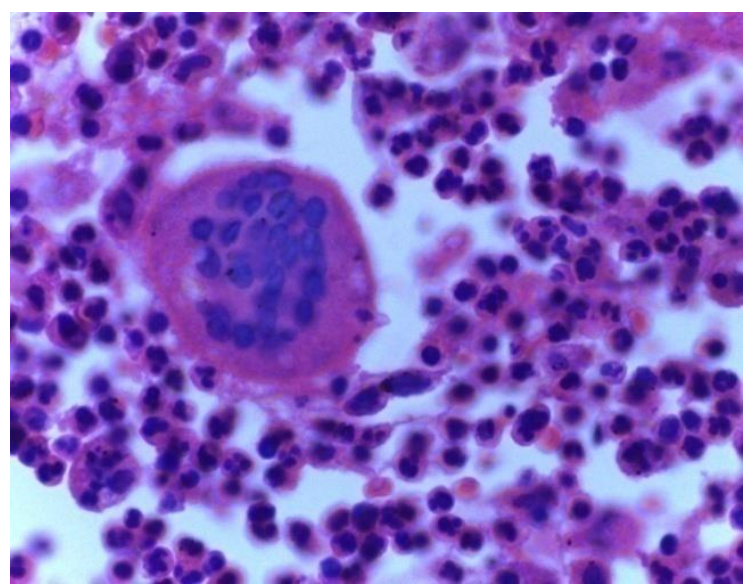

Fig. 2b: Chronic Granulomatous Inflammation, H \& E X 100.

Post-operative period was uneventful with wound healed. He was referred to the endemic disease unit for further management.

\section{Discussion}

Specialized cells grouped together represent a section of the body's defense system known as lymph nodes. The cervical, axillary and inguinal constitute the peripheral group readily palpable by clinical examination (Abba \& Khalil 2012). Chronic peripheral LAP represents pathology of which $\mathrm{Tb}$ is the commonest in the developing countries (Asuquo et al 2013), this is keeping with this presentation, Figure 1.

Seven to thirty percent $(7-30 \%)$ of $\mathrm{Tb}$ are extra pulmonary of which lymphadenitis represents $17-43 \%$. There has been an increase in recent years of extra pulmonary $\mathrm{Tb}$ including the subset of LAP in non HIV patients (Nwagbara et al 2013, Fontallina et al 2011). This is keeping with the authors experience in 2 years (Cervical-4, axillary-1, inguinal-1), (Nwagbara et al 2013, Nwagbara V et al 2013, Asuquo et al 2013). Increase has also been reported (non-HIV and HIV) in extra pulmonary cases of $\mathrm{Tb}$ including the peripheral subset of LAP in Asia and Africa, however, the overall rates of pulmonary tuberculosis (PTB) in the US have continued to decrease (Nwagbara V et al 2013). Tuberculosis is still a major health problem as the World Health Organization (WHO) in 2013 reported that 9 million people were ill from Tb among 1.1 million with HIV. Isolated tuberculous inguinal LAP is a rare entity and usually bilateral. Guler E et al reported unilateral isolated (right) inguinal LAP in keeping with this report (left) (Guler et al 2007).

Tuberculous LAP is reported to affect more females than males with a peak age of 20-40 years (Sing \& Tiwari 2016). Muluye D et al reported tuberculous LAP to be common in patient younger than 30 years [15-24 years $(28.5 \%), 25-34$ years $(27.6 \%)$, ( Muleye et al 2013), our patient aged 16 years had the first episode 2 years earlier at 14 years. Inguinal LAP is rare and ranked $3^{\text {rd }}$ (4.3\%) among Tuberculous peripheral LAP, while cervical and axillary ranked $1^{\text {st }}(74.2 \%)$ and $2^{\text {nd }}(20.3 \%)$ respectively (Muleye et al 2013). Tuberculous inguinal LAP presents usually as a bilateral disease, isolated unilateral LAP is very rare representing a distinct disease entity usually not related to Tb of the lungs and bowel in keeping with this report (Vagholkar et al 2016). Vagholar K et al reported cervical (75-90\%), axillary (14-20\%) and inguinal (4-8\%) in decreasing order of frequency (Vagholkar et al 2016). However, Dandapat et al reported that in the Indian subcontinent, inguinal lymph node involvement is more common than axillary (Dandapat et al 1990).

The tonsil, adenoids are easy portals of entry for inhaled mycobacterium; hence tuberculous LAP is largely confined to the cervical lymph nodes (Shubha et al 2010). However, lymphatic or haematogenous spread from an original focus in the lung may provide another source for tuberculous LAP (Shubha et al 2010). The other portals of entry may be through the intestines and rarely through the skin (Kar et al 2011). In isolated cases, there is usually no evidence of past or active lesion elsewhere as typified by this report. Guler E et al reported 67 cases LAP in UK with only 3 cases in the inguinal region. Two cases of isolated unilateral inguinal tuberculous LAP have been described one each in India and Greece (Guler et al 2007).

Painless mass is the most common form of presentation, in the later stages there may be caseation as was our experience that may result in ulceration and formation of multiple sinuses, notably past history of $\mathrm{Tb}$ is obtained only in about $9.8 \%$ (Sing \& Tiwari 2016). Clinical diagnosis requires a high index of suspicion in patients presenting with peripheral LAP in regions where $\mathrm{Tb}$ is more prevalent even in apparently healthy patients. In the absence of the history of exposure to $\mathrm{Tb}$, detection of calcifications on radiography should arouse the possibility of $\mathrm{Tb}$ (Fugi et al 2003). Fine needle aspiration cytology (FNAC) is accepted as safe and cost effective in the diagnosis of tuberculous LAP with the cytological pattern of epitheloid granuloma with casseous necrosis (Sing \& Tiwari 2016). Excision biopsy though invasive has the highest sensitivity (80\%), the finding of granulomatous features on histology is suggestive of $\mathrm{Tb}$ (Sing \& Tiwari 2016, Asuquo et al 2013, Fontallina et al 2011). In the treatment of tuberculous LAP, response is good with directly observed treatment short (DOTS) course based on WHO guidelines. However, in the presence of complications surgery may be required (Sing \& Tiwari 2016), Kar et al 2011)

\section{Conclusion}

Sustained health education is essential for early presentation. Physicians are requested to subject chronic LAP to histological evaluation for early diagnosis and appropriate treatment for improved outcomes. Tuberculosis should be considered as a differential diagnosis in isolated chronic peripheral inguinal Lymphadenopathy especially in developing countries where $\mathrm{Tb}$ is more prevalent. 


\section{References}

[1] Nwagbara VI, Asuquo ME, Akpan S, Nwachukwu IE, Nnoli M, Ugbem T (2013) Tuberculous axillary lymphadenopathy: A case report. J Trop Dis 1: 113

[2] Muluye D, Biadgo B, Waldegerima E, Ambachew A (2013) Prevalence of tuberculous lymphadenitis in Gonder University Hospital, North West Ethiopia. BMC Public Health 13: 435 https://doi.org/10.1186/1471-2458-13-435.

[3] Nwagbara VI, Asuquo ME, Ebughe G, Agbor C, Akpan S, Ugbem T, Asuquo IM (2013) Tuberculous lymphadenitis of the neck: case series. International Journal of Medicine 1 (1): 4-8.

[4] Sing SK, Tiwari KK (2016) Tuberculous lymphadenopathy: Experience from the referral centre of Northern India. Niger Med J 57: 134-138. https://doi.org/10.4103/0300-1652.182077.

[5] Guler E, Guler S, Ucmak H, Eren Dagli C, Davutoghi M (2007) An unusual presentation of extra pulmonary tuberculosis in an adolescent: Isolated unilateral inguinal lymphadenitis. Turk J Med Sci 37(6):387-389.

[6] Asuquo ME, Nwagbara VI, Akpan S, Ebughe G, Ugbem T, Asuquo IM (2013) Non-caseating submental tuberculous lymphadenopathy: A case report. Case Reports in Clinical Medicine 2(5): 291-293. https://doi.org/10.4236/crcm.2013.25078.

[7] Abba AA, Khalil MZ (2012) Clinical approach to lymphadenopathy. Annals of Nigerian Medicine 6(1): 11-17. https://doi.org/10.4103/0331-3131.100201.

[8] Fontallina JM, Barnes A, von Reyn CF (2011) Current diagnosis and Management of peripheral tuberculous lymphadenopathy. Clin Infect Dis 53: 555-562. https://doi.org/10.1093/cid/cir454

[9] Vagholkar K, Pawanarkar A, Vagholkar S, Iyengar M, Pathan S, Patel A (2016) Isolated Tuberculous lymphadenopathy: a diagnostic challenge. International Journal of Research in Medical Sciences 4(4): 1251-1253. https://doi.org/10.18203/23206012.ijrms20160733.

[10] Dandapat MC, Mishra BM, Dash SP, Kar PK (1990) Periphera lymph node tuberculosis: A review of 80 cases. Br J Surg 77: 911 912. https://doi.org/10.1002/bjs.1800770823.

[11] Shubha AB, Sapna H, Dinash Rao B (2010) Tuberculous lymphadenitis presenting a diagnostic dilemma: A case report. International Journal of Dental Clinics 2: 48-52.

[12] Kar JK, Manoronian K, Maiti C (2011) Tuberculosis in the left inguinal region associated with cutaneous tuberculosis of left second toe. An unusual presentation of extra pulmonary tuberculosis. Annals of Nigerian Medicine 5(2): 59-61. https://doi.org/10.4103/0331-3131.92952.

[13] Fugi T, Kimura M, Yanagita Y, Koida T, Kuwano H (2003) Tuberculosis of axillary lymph nodes with primary breast cancer Breast cancer 10: 175-178. https://doi.org/10.1007/BF02967646. 